\title{
A Decision Model for Hotel Revenue Management Displacement Analysis for Transient Room Demand vs. Group Room Demand
}

Stephen C Morse ${ }^{1 *}$ and Eric Beckman ${ }^{2}$

${ }^{1}$ College of Business, Hospitality and tourism Management, Western Carolina University, North Carolina, USA

${ }^{2}$ Chaplin School of Hospitality and Tourism, Florida International University, Florida, USA

\begin{abstract}
Revenue management in the hotel industry involves measuring the trade-off of revenue of one type of business over another type of business. One of the major decisions involves choosing revenues generated by transient (individual) room demand vs. revenue generated by group room demand. Traditionally, this decision was relatively straight forward as one would compare the ADR generated revenue for transient vs. group demand, and chose the type of business that maximized revenue. The decision model developed in this study shows there are many additional variables beside ADR generated revenue to consider with this business decision and trade-off of transient vs. group demand. Incorporated into this decision model are additional variables important to the decision like ancillary non-room revenue such as catering, food and beverage sale, meeting room rental, audio/visual services and other activities.
\end{abstract}

Keywords: Constriats; Customer business; Revenue management; Revenue; Sales; Retail

\section{Introduction and Purpose}

In addition to the decision analysis of hotel rates for different market segments of customers, hotel revenue management strategies also include decisions to accept a mix of transient (individual) room demand vs. group room sales. The objective of hotel revenue management strategies are to maximize revenues from selling hotels rooms and ancillary hotel services in an environment with supply capacity constraints. Displacement is defined as accepting one type of customer business and displacing (not accepting) another type of customer business. The purpose of this study is to develop a displacement analysis decision model that identifies revenue variables, capacity constraints, and decision criteria in making decisions on the acceptance of transient room demand vs. group room demand.

\section{Background}

Orkin [1] defines hotel revenue management as the analysis of a set of decision variables attempting to maximize potential hotel revenues using a variety of strategies. Kimes [2] defines revenue management as "the process of allocating the right type of capacity to the right type of customer at the right price so as to maximize revenue or yield."

Cullen and Helsel [3] state that one of the major revenue management decisions is the choice to accept transient (individual) room demand vs. group demand. The displacement decision analysis involves many variables that compares expected hotel revenues from the usually higher Average Daily Rates (ADR) generated from transient demand vs. lower ADR's generated from group room demand. However, group room demand has the potential to generate additional ancillary non-room revenue such as catering, food and beverage sale, meeting room rental, audio/visual services and other activities. Pinchuk [4] states that existing revenue management systems should be called displacement optimization analysis since the essence of revenue management is to measure the trade-off of revenue of one type of business over another type of business. In this study, the displacement analysis model and decision criteria identifies essential variables and their relationships in choosing the mix of transient room demand vs. group room demand that will maximize hotel revenues from room and non-room (ancillary) sources.

\section{Displacement Analysis Model}

The displacement analysis model and decision criteria are expressed as:

\section{EGDRev=ETGRev - ETDTRev, where:}

EGDRev=Expected Group Displaced Revenue (the amount of revenue from accepting group demand and displaced by losing transient demand), and

ETGRev=Expected Total Group Revenue (group rooms sales+ancillary group sales), and

ETDTRev=Expected Total Displaced Transient Revenue (loss in transient room sales+ancillary sales).

The decision criteria to accept quoted group room demand is:

EGDRev $>0$, accept group demand offer (i.e. ETGRev $>$ ETDTRev; the expected revenue from the group demand is higher than the expected revenue from transient demand),

$\mathrm{EGDRev}=0$, decision is indifferent (i.e. ETGRev=ETDTRev; the expected revenue from group demand is equal to the expected revenue from transient demand), and if

EGDRev $<0$, do not accept group demand offer (i.e. ETGRev $<$ ETDTRev; the expected revenue from group demand is less than the expected revenue from transient demand).

\section{General Model}

A general model is stated as:

${ }^{*}$ Corresponding author: Stephen C. Morse, College of Business, Hospitality and tourism Management, Western Carolina University, North Carolina, USA, Tel: (828) 227-3386, E-mail: scmorse@wcu.edu

Received July 28, 2016; Accepted August 24, 2016; Published September 01 2016

Citation: Morse SC, Beckman E (2016) A Decision Model for Hotel Revenue Management Displacement Analysis for Transient Room Demand vs. Group Room Demand. J Hotel Bus Manage 5: 141. doi: 10.4172/2169-0286.1000141

Copyright: ( 2016 Morse SC, et al. This is an open-access article distributed under the terms of the Creative Commons Attribution License, which permits unrestricted use, distribution, and reproduction in any medium, provided the original author and source are credited. 
Citation: Morse SC, Beckman E (2016) A Decision Model for Hotel Revenue Management Displacement Analysis for Transient Room Demand vs. Group Room Demand. J Hotel Bus Manage 5: 141. doi: 10.4172/2169-0286.1000141

Page 2 of 2

ETGRev $=(B) F+G+H$, where:

$\mathrm{B}=$ Group nights requested times probability factor of per cent of group showing $(0-100 \%$ wash factor),

$\mathrm{G}=\mathrm{Group}$ food and beverage revenue quoted,

$\mathrm{H}=$ Group meeting space and other ancillary revenue quoted, (A/V rental, set-up, retail), and

$\mathrm{F}=$ Group Average Daily Rate quoted.

and

ETDTRev $=(A-B) C+(A-B) D+E(C)+E(D)$, which is algebraically reduced to:

ETDTRev $=((A-B)+E)(C+D)$, where:

$\mathrm{A}=$ Rooms remaining after subtracting previous reserved/booked transient rooms, previous reserved/booked group rooms, and forecasted (estimated) transient room demand pick-up,

$\mathrm{C}=$ Transient Average Daily Rate, (TADR),

$\mathrm{D}=$ Transient Average Ancillary Revenue per Day per room (TAARev) (food \& beverage, retail, spa),

E=Displacement of transient room demand based on Transient Average Length of Stay (TALOS) in pre- and post-group sales dates, (transient overlap factor - for example if group requests Wed. \& Thurs., and transient ALOS is two days, then some transient displacement will overlap and occur on Tues. before and Fri. after group stay for transients planning to stay Wed. \& Thurs.).

\section{Specific Model}

Specifically, each variable of the displacement model is expressed as:

$\mathrm{A}=\sum \mathrm{ni}=1[(\mathrm{THCi}-($ TransDResi+GroupDResi $))-$ ETDRi $]$,

$\mathrm{B}=\sum \mathrm{ni}=1$ (GNReqi) (Prob),

$\mathrm{C}=\mathrm{TADR} i$,

$\mathrm{D}=$ TAARevi,

$\mathrm{E}=\mathrm{TALSO},=[(\mathrm{TALSO}) 2-\mathrm{TALSO}]$,

$\mathrm{F}=\mathrm{GADR}$,

$\mathrm{G}=\mathrm{GFBRevi}$, and

$\mathrm{H}=\mathrm{GMeetRevi}$.

Where:

$\mathrm{i}=1 \ldots \mathrm{n}$,

$\mathrm{n}=$ total nights stayed,

THCi=Total Hotel Capacity on night $\mathrm{i}$,

TransDResi=Transient Demand for Rooms reserved on the books on night $\mathrm{i}$,

GroupDResi=Group Demand for rooms reserved on books for night i,

ETDRi=Estimated Transient Demand for rooms on night $\mathrm{i}$,

GNReq1, $\mathrm{n}=$ Group Nights Requested 1 to $\mathrm{n}$,

GADR=Group Avg. Daily Rate quoted,
Prob=probability show-rate or wash out factor of group (0-100\%)

TAARevi=Transient Average Ancillary Revenue per room for night $\mathrm{i}$,

TALSO1, $\mathrm{n}=$ Transient Average Length of Stay for pre- and postgroup overlap period 1, n, GFBRev1,n=Group Food \& Beverage Revenue quoted for period 1 to $n$, and

GMeetRev1, $\mathrm{n}=$ Group Meeting Revenue quoted for period 1 to $\mathrm{n}$ (from meeting room rental, A/V equipment and ancillary sales).

Specifically, the relationship among the variables in the model is:

ETGRev $=\Sigma_{-}(\mathrm{i}=1) \wedge \mathrm{n}[($ GNReqi $)($ GADR $)+$ GFBRevi+GMeetRevi], and

ETDTRev $=\sum \_(\mathrm{i}=1)^{\wedge} \mathrm{n}[[\mathrm{THCi}-($ TransDResi+GroupDResi) $]-$ ETDRi $]$ - [(GNReqi) (Prob)(TADRi)]+[[THCi - (TransDResi+GroupDResi)] - ETDRi $]$ - [(GNReqi)(Prob)(TAARevi) $]+[[($ TALOS $) 2$ - TALOS $]$ (TADRi) $]+[[($ TALOS $) 2$ - TALOS](TAARevi)].

\section{Conclusion}

The development of this hotel revenue management displacement model shows that when making trade-offs and decisions regarding transient room demand vs. group room demand, many factors can influence this decision. While on the surface, it appears the decision to accept transient or group business fell primarily on the comparison of ADR of transient vs. group business, this decision model shows the relationship and importance of many other variables in making these decisions and the quantitative decision making process to maximize revenues under revenue management practices. Thus, additional variables such as ancillary non-room revenue such as catering, food and beverage sale, meeting room rental, audio/visual services and other activities are shown to have important roles in this decision making model.

\section{References}

1. Orkin EB (1988) Boosting your bottom line with Yield Management. The Cornel Hotel and Restaurant Administration Quarterly. 28: 52-56.

2. Kimes SE (1989) The basics of yield management. The Cornell Hotel and Restaurant Administration Quarterly. 30: 14-19.

3. Cullen K, Helsel C (2006) Defining Revenue Management: Top Line to Bottom Line. Hospitality Sales and Marketing Association International Foundation Special Report.

4. Pinchuk $S$ (2007) Should revenue management be called displacement optimization? Journal of Revenue and Pricing Management 6: 264-268. 